\title{
Racial and Socioeconomic Disparities in Heat-Related Health Effects and Their Mechanisms: a Review
}

\author{
Carina J. Gronlund
}

Published online: 1 July 2014

(C) Springer International Publishing AG 2014

\begin{abstract}
Adaptation to increasing extreme heat in a changing climate requires a precise understanding of who is most vulnerable to the health effects of extreme heat. The evidence for race, ethnicity, income, education, and occupation at both the individual and area levels as indicators of vulnerability is reviewed. The evidence for the social, behavioral, and technological mechanisms by which racial and socioeconomic disparities in vulnerability exist is also reviewed. These characteristics include cardiorespiratory, renal and endocrine comorbidities; cognitive, mental, or physical disabilities; medication use; housing characteristics; neighborhood characteristics such as urban heat islands, crime, and safety; social isolation; and individual behaviors such as air conditioning use, opening windows, using fans, and use of cooler public spaces. Pre-existing and future research identifying these more proximal indicators of vulnerability will provide information that is more generalizable across locations and time to aid in identifying who to target for prevention of heat-associated morbidity and mortality.
\end{abstract}

Keywords Climate change $\cdot$ Race $\cdot$ Socioeconomic . Sociodemographic $\cdot$ Temperature $\cdot$ Heat $\cdot$ Heat wave . Susceptibility $\cdot$ Vulnerability $\cdot$ Disparities $\cdot$ Health $\cdot$ Morbidity · Mortality · Air conditioning · Social isolation . Income $\cdot$ Occupation $\cdot$ Education $\cdot$ Housing $\cdot$ Urban heat island $\cdot$ Vegetation $\cdot$ Impervious surface $\cdot$ Risk perception . Crime $\cdot$ Medication

\section{J. Gronlund $(\bowtie)$}

Center for Social Epidemiology and Population Health, Department of Epidemiology, University of Michigan School of Public Health, 1415 Washington Heights, Ann Arbor, MI 48109-2029, USA

e-mail: gronlund@umich.edu

\section{Introduction}

Associations between high outdoor temperatures and health have been studied for many decades, particularly in occupational settings $[1 \bullet \cdot, 2,3]$, and with regard to specific extreme heat events, or heat waves [4]. With heat waves already increasing, and likely to continue to increase in frequency, intensity and duration due to climate change [5], interest in the health effects of heat has broadened. To adapt to extreme heat, it is important to precisely understand who is most vulnerable to the health effects of extreme heat. There are many studies of the associations of temperature with mortality, hospital admissions, emergency room visits, and calls for ambulances; these studies have been reviewed previously $[1 \bullet \bullet, 6,7 \bullet, 8 \bullet, 9 \bullet \bullet, 10 \bullet$, $11 \bullet \bullet, 12-31]$. Many of these summaries also address vulnerability by racial and socioeconomic characteristics. In contrast to previous work, this review will focus specifically on the racial, ethnic, and socioeconomic (i.e., education, income, and occupation) characteristics of vulnerability and on the potential mediators of these characteristics - the more proximate, or "downstream," health and behavioral mechanisms by which certain people are both exposed to higher temperatures and are more susceptible to, or more adversely affected by, higher temperatures.

The more proximate indicators of vulnerability, described in Fig. 1 and below, include characteristics of physiologic susceptibility such as medication use and poor cardiorespiratory, renal or endocrine health. Additional indicators of vulnerability include heat risk perception, cultural or linguistic isolation, housing characteristics, and neighborhood characteristics such as crime and safety and urban heat islands. These characteristics may in turn influence heat exposure directly or via air conditioning use, window and fan use, or travel to and use of cooler public spaces. 


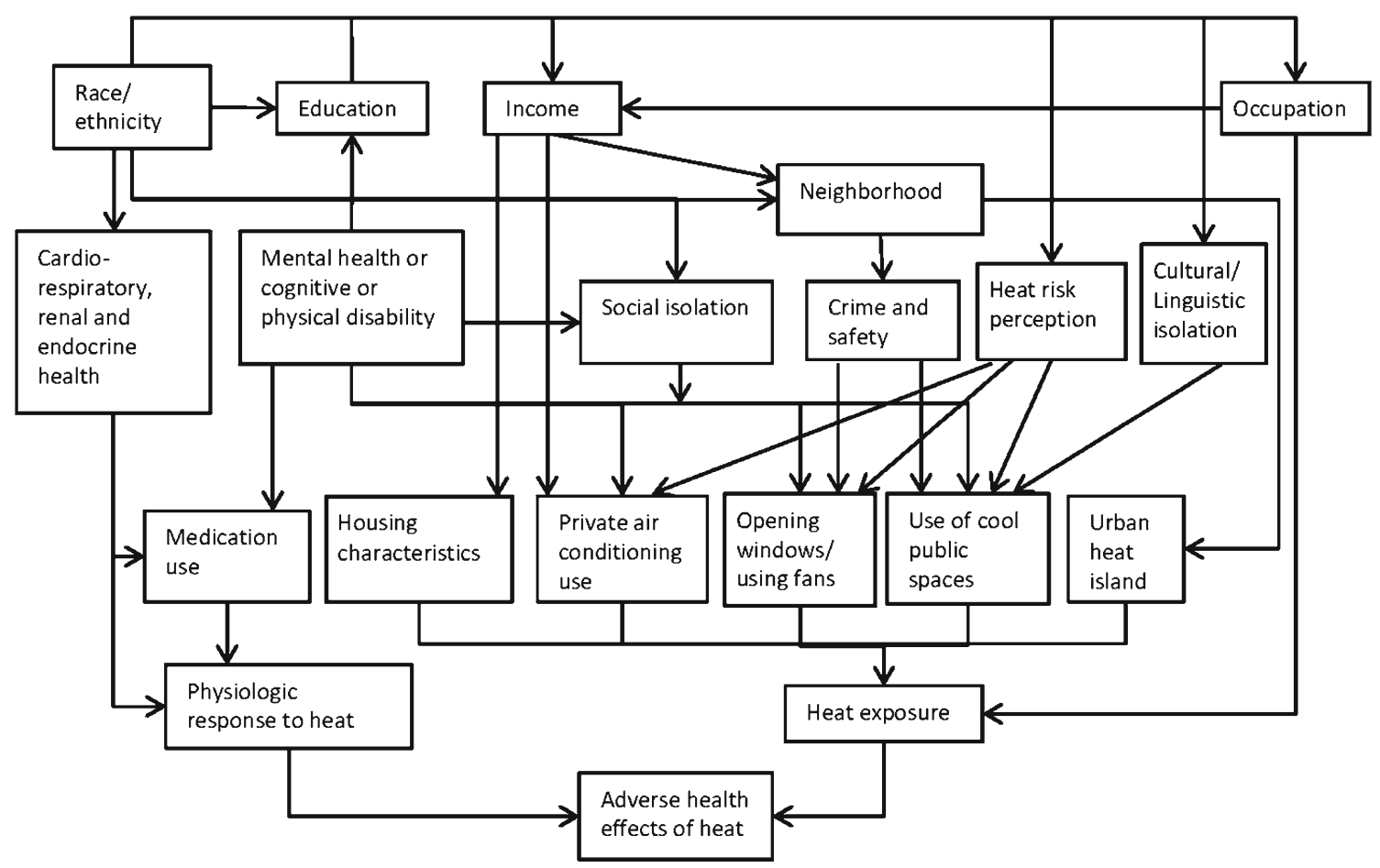

Fig. 1 Associations between racial and socioeconomic characteristics and more proximal determinants of adverse health effects of heat

\section{Challenges and Opportunities in Understanding Susceptibility to Heat Health Effects}

Unlike many other environmental exposures, such as air pollution or lead, heat exposure is usually readily perceived by the exposed individuals. For many people, it is relatively easy to decrease personal exposure to heat, such that their actual exposures are lower than the temperatures measured at outdoor monitoring stations on a day-to-day basis. This means that estimates of individual heat exposure are often imprecise in studies of heat health effects.

However, because individuals' actions and/or ability to reduce a perceived heat exposure are often patterned by socio-economic, cultural, and other factors, researchers can gather evidence on social and behavioral modifiers of temperature and health associations using a wide range of study designs. These designs include not only secondary data analyses of previously gathered cohort data or administrative records (which may have large sample sizes but crude information on socioeconomic characteristics), but also smaller surveys and case-control and qualitative studies in which individuals or surrogates are interviewed specifically about barriers to staying cool during extreme heat [26, 32••, 33, 34••, 35••, 36••, 37-42].

Heat-associated mortality decreases as latitude decreases $[19,43]$, and this may be due not only to behavioral and technological adaptation but also to physiologic adaptation. Individuals can acclimate through heat-stress-induced physiologic changes which improve thermoregulation [18].
Therefore, physiologic responses to heat may vary widely by climate, making it difficult to apply study results from one location to another location if climate conditions are unique.

A challenge to studying racial and socioeconomic disparities in heat-health effects is that these characteristics are often correlated with one another. For example, in Detroit, Michigan, the census tract percentages of individuals of nonwhite race, living below the poverty level, disabled and with less education, and of imperviousness (i.e., heat-retaining surfaces impervious to water) are moderately correlated with each other [44]. This makes it difficult to identify the mechanisms of heat vulnerability and to understand the relative magnitudes of their effects on heat-related morbidity and mortality.

\section{Race/Ethnicity}

Individual racial and ethnic identity is often strongly associated with heat-associated morbidity and mortality in the USA. For example, blacks have often been found to have increased

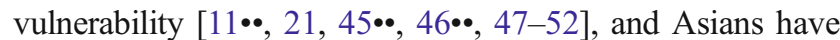
been found to have decreased vulnerability [49]. However, some studies have not found race or ethnicity to be associated with heat-associated health effects [53, 54•, 55••]; and in a study of high temperatures and emergency room visits for various cardio-respiratory diseases in California, when compared to whites, risks were higher among Hispanics for some 
diseases and lower among blacks, Hispanics or Asians for others [56]. These studies largely did not control for other characteristics of vulnerability. Neighborhood or community racial and ethnic composition has been found to be a factor in heat-associated morbidity and mortality in some studies [57] but not in other studies [45••, 58].

Evidence of racial differences in heat tolerance due to genetic differences is inconclusive at best $[10 \bullet \bullet, 59,60]$. Racial and ethnic disparities in heat-associated morbidity and mortality are probably mainly attributable to more distal characteristics of vulnerability, at least in the USA. Being a racial or ethnic minority in the USA is associated with lower income, poorer physical health, living in an area with sparse vegetation and more heat-absorbing surfaces, lower air conditioning ownership and/or outdoor farming work [34••, 61-63].

Hispanic ethnicity in the USA is often associated with decreased social isolation and better health [64]; increased social cohesion is thought to have played a role in lower heat-related mortality rates during the 1995 Chicago heat wave among Hispanics, when compared to non-Hispanic whites $[10 \bullet \bullet, 65]$. Additionally, a survey of Phoenix, Arizona residents found Hispanics to be more likely to perceive ambient heat as a risk [66], suggesting another mechanism by which Hispanic ethnicity can be associated with decreased risk of heat health effects. However, in contrast to the studies in Chicago, studies in New York and Phoenix found that Hispanic ethnicity and residing in a Hispanic neighborhood were associated with increased heat health-effects $[46 \bullet \bullet, 50,57]$. Furthermore, in Phoenix, this association was independent of linguistic isolation, which was also associated with heat vulnerability, perhaps because linguistically isolated individuals may not understand heat warnings [57], understand heat-health educational messages, or be familiar yet with the local climate. Interviewees expressed concerns that the linguistic isolation of elderly immigrants increased social isolation in Australia [39]. Additionally, race or ethnicity may be a proxy for cultural isolation and a reluctance to travel to cooler public spaces because of a lack of familiar food and activities or because of concerns around immigration status and possible deportation [32••].

\section{Socioeconomic/Sociodemographic Position}

Several studies have used summary measures of socioeconomic or sociodemographic position in assessing vulnerability to heat-associated morbidity or mortality, and have found these to be characteristics of vulnerability $[4,67]$. For example, heat-related hospital admission was associated with lower socioeconomic status at the individual level in Adelaide, Australia, controlling for other characteristics [68]. Other studies used an area measure of socioeconomic status. A study in Georgia, USA, found middle, but not lower socioeconomic status (as defined by family structure, housing, education, and employment in a census block group), to be associated with increased emergency department admissions for heat illnesses [55••]. A study in Hong Kong found increased vulnerability among people living in low socioeconomic districts [69•]. In Phoenix, Arizona, neighborhood socioeconomic vulnerability was an important predictor of heat-related death in a census block group [63]. However, other studies did not find modification by area-level socioeconomic position [70].

Summary measures of socioeconomic or sociodemographic position provide the advantage of modeling the latent class represented by the combination of these factors, which may influence vulnerability beyond the individual effects of the components. This approach also has statistical advantages when the components are strongly correlated. However, a summary measure does not provide information on the individual effects of income, education, or occupation on heat vulnerability. In contrast, the studies reviewed below evaluated education, income, and occupation as distinct characteristics.

\section{Education}

Some studies in both the USA [48] and Europe [67, 71] have found higher heat-associated mortality among individuals with less education. However, other studies have not found education to be a characteristic of vulnerability to heatassociated mortality in the USA [47, 72], Latin America [73], or China [74-76]. Educational attainment is not usually recorded in hospital or emergency department admissions records in the USA, so this characteristic has not been well studied with regards to heat morbidity. Higher education was protective against heat-associated morbidity in the 2003 heat wave in Europe [41]. In Rome, less education was associated with a higher risk of heat-associated pre-term birth [77]. Neighborhood educational composition has been associated with heat-associated mortality [45••], but results have been mixed when assessing education effects at the community level $[43,58]$.

Similarly to race, education may only be related to heat vulnerability very distally. Differences in heat-associated health outcomes by educational attainment are probably mediated by a variety of factors such as income disparities, occupational differences (work in climate-controlled settings is more likely to be performed by more highly educated individuals), cognitive deficits, other health-related barriers to education, or lack of knowledge about heat-health risk [78]. In the absence of information on the more proximate mechanisms, race and perhaps education should be accounted for when deciding which people and places to target for adaptation measures in areas where they have been identified as important characteristics of heat vulnerability. However, 
more proximate characteristics of vulnerability would probably more accurately identify vulnerable individuals, and public health measures targeting the more proximate mechanisms would likely be more effective.

\section{Income}

An individual's income is usually not recorded in mortality or morbidity administrative records, but studies have found income or poverty to be related to heat-associated mortality in the USA at the neighborhood level [54•] and at the community level [58], in China at the neighborhood level [69•], and in Japan at the community level [79•]. Income has been found to be associated with hospital admissions during elevated heat at the block levels in the USA [46••] and in Italy [80] as well.

These associations may exist because individuals with low incomes may be more reluctant to respond to warnings [66] or to pay for transportation to cooler locations [32••, 39]. Additionally, surveys and qualitative studies have repeatedly identified concerns over the utility costs of operating an air conditioner as being a major barrier to staying cool $[32 \bullet \bullet, 33$, $36 \bullet$, 39]. Furthermore, low income may be a barrier to receiving adequate medical care prior to a heat event. Lack of private health insurance was significantly associated with heat-related hospitalization, when controlling for other factors in a study of inpatients during a 2009 heat wave in Adelaide [68].

\section{Occupation}

Working in an environment that is not climate-controlled is an important risk factor for heat health effects. Controlling for other health and socio-demographic factors, a case-control study of mortality from the 2003 heat wave in France identified manual workers as having been at increased risk [81]. Among slum dwellers in Gujarat, India, occupation was independently associated with heat illness [82]. A recent review of occupational heat exposure included studies of miners, construction workers, farm laborers, first responders, and military personnel. This review emphasized that heat-related illness may be the most common cause of nonfatal environmental emergency department admission in the USA across all age groups, and that overweight, lack of acclimatization, and use of personal protective equipment can increase the risks of heat-related illness. Military discipline or business pressures may also drive these workers to the point of serious adverse

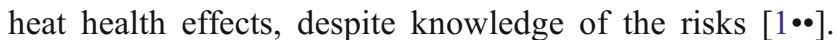
However, interviews of hired farm workers in California did suggest a need for increased education regarding heat-related illness [34••]. Farm workers and day laborers also tend to have lower incomes and to be racial or ethnic minorities $[1 \bullet \bullet]$ and therefore are susceptible to the risks associated with these characteristics, as described above.

\section{Proximal Mechanisms of Heat Exposure and Susceptibility}

Health and Medication Use

Numerous studies have found associations between heat and deaths, hospitalizations, or emergency room visits for specific diseases (besides dehydration and heat stroke), including cardiovascular diseases, respiratory diseases, cerebrovascular diseases, diabetes, renal disease, physical disabilities, psychiatric

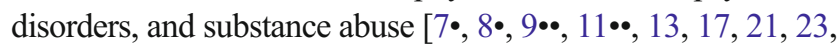
$28,46 \bullet \bullet, 56,58,83,84]$. With the exception of myocardial infarction, it is likely that the deaths and hospitalizations associated with these diseases reflect a greater susceptibility to heat among individuals who had these diseases prior to the heat event, rather than a causal association between heat and onset of the disease. Other observational studies have addressed physiologic susceptibility more directly, finding susceptibility to death or hospitalization during extreme heat among people with these pre-existing conditions [26, 35••, 45••, 51, 68, 82, $85,86]$. Laboratory studies have shown that cooling is achieved physiologically through increased blood flow to the skin and sweating and that these cooling mechanisms rely heavily on the cardiovascular system, as well as on the endocrine, urinary and integumentary processes $[18,20,87]$. Therefore, individuals with pre-existing conditions which compromise these processes are likely more susceptible to heat. Additionally, individuals with poor mental health may be less able to take actions to reduce their exposure to extreme heat [35••, 88]. There is also evidence that many of the drugs used to treat these physical and mental conditions (such as anticholinergic, antihypertensive, and antipsychotics drugs) reduce sensory perception of ambient heat, or suppress or inhibit thermoregulatory responses (such as thirst), thereby increasing the risk of an adverse heat-related health event [30, 35••, 39, 89-96]. However, the relative influences on heat susceptibility of the medications vs. the underlying diseases are unclear.

\section{Crime and Safety}

Research examining the role of crime or safety concerns in discouraging cooling behaviors is limited. An ethnographic study of the 1995 Chicago heat wave, for example, indicated that some of its victims chose not to open their windows or travel to cooler locations because of fears of crime [65]. In qualitative interviews of the elderly in the USA and Australia, respondents cited crime and safety concerns and fears of assault as barriers to opening windows or traveling to cooler locations $[32 \bullet \bullet, 39]$. 


\section{Heat Risk Perception}

Studies in Canada, the UK and the USA have identified a wide range of attitudes towards the risks associated with heat in their respective populations. Often, elderly respondents incongruously expressed heat as something that other "old" people were vulnerable to, but not themselves [32••, 97]. Respondents in a study in Australia expressed ambivalence or held individualistic attitudes towards heat, reporting high air conditioning use, swimming, acclimatization and personal resilience to heat [36••]. Most respondents in Canadian studies did perceive heat as a personal risk and also reported that they would take actions to stay cool during extreme heat $[40,98]$. Finally, the perceived risk of heat was not predictive of air conditioning use among residents with poor cardio-respiratory health in Montreal [37], suggesting that low perceived risk is not always a barrier to staying cool.

\section{Air Conditioning}

Air conditioning is a powerful means of reducing exposure to heat. In studies in the USA, associations between heat and mortality are reduced or absent in communities or ZIP codes with high air conditioning prevalence [43, 58, 62, 99-102]. Similarly, reduced heat-mortality associations are seen in analyses of individual air conditioning ownership during heat wave events $[26,81]$. Air conditioning also has the added benefit of reducing exposure to ambient air pollution [103, 104]. However, air conditioning ownership was not associated with self-reported heat illness in a study in Canada [40]. As discussed above, having the cognitive and financial abilities to operate the air conditioner is also important.

Air conditioning use does have substantial drawbacks. Its use may actually increase vulnerability because during blackouts, air conditioning is not available as a cooling strategy, and individuals who have come to depend on it, or who have not acclimated to outdoor temperatures, may not be able to adequately cool themselves by other means during extreme heat $[38,39,105]$. Also, in countries dependent on fossil fuels for electricity production, the electricity generated to operate air conditioners contributes to greenhouse gas emissions and therefore to climate change. Efforts to Increase air conditioning access and use should do so as sustainably as possible, with efficient technologies accompanied by weatherization of the buildings, and ideally should target communal spaces.

\section{Opening Windows and Using Fans}

Natural ventilation is a long-standing and effective cooling technique. Having a working fan was suggestive of being protective against death during heat waves in a metaanalysis [26]. Furthermore, surveys and interviews have identified fan and window use as a common method for staying cool $[32 \bullet \bullet, 33,40]$, although fans can be harmful when used to circulate hot air rather than cool air [32••].

\section{Use of Cool Public Spaces}

Traveling to cooling centers or cooler locations has also been identified as an effective technique to staying cool. In a metaanalysis of deaths during heat waves, visiting other airconditioned places was highly protective [26]. However, studies suggest that opportunities exist for improving cooling center awareness and use in the USA and Canada $[32 \bullet \bullet, 40]$.

\section{Social, Cultural and Linguistic Isolation}

Social isolation is often found to be associated with adverse health effects from heat. In studies of heat-wave associated mortality, being unmarried or widowed, living alone, or not leaving home were all identified as risk factors [26, 80, 85]. Interviewees in Australia and the USA have identified social, cultural, and linguistic isolation as risk factors for heatassociated illnesses [32••, 39, 65].

Social isolation may be a consequence of a mental, physical, or cognitive impairment, but it may also modify the effects of these impairments such that socially isolated individuals (who are not able to adequately decrease their exposure to heat by cooling their homes or traveling to cooler locations) may be more vulnerable to extreme heat than individuals who do have assistance.

\section{Urban Heat Island}

Results have been mixed among studies of urban heat island characteristics and heat-associated health effects. Studies in US cities as well as of specific cities such as Montreal, Barcelona, Hong Kong, and Taiwan have found associations between heat-associated health effects and remotely sensed land surface temperature, imperviousness or vegetation [45 •, 57, 63, 106, 107, 108•]. However, studies in Philadelphia and Worcester, Massachusetts did not find effects of vegetation or imperviousness [54, 57]. In a case-control study of the 2003 heat wave in France, the surface temperature around the decedent's building was associated with increased mortality [81].

\section{Housing}

Housing characteristics have also been associated with heathealth outcomes [38]. In the 2003 heat wave in France, having a well-insulated home was protective against heat-related mortality [81]. In Barcelona, heat-associated mortality was greater in census tracts with older buildings, adjusting for other census tract characteristics [108•]. However, in the 1995 and 1999 Chicago heat waves, housing characteristics 
(such as the floor the decedent resided on) were not found to be significant characteristics of vulnerability, after controlling for other characteristics of vulnerability [86, 109].

\section{Conclusions}

Racial and socioeconomic characteristics have been found to be associated with increased susceptibility to heat-associated health effects in some studies but not in others. Occupation is directly associated with risk of heat-related health effects, but associations with race, education, and income are likely mediated by characteristics such as use of air conditioning or cool environments, comorbidities, medication use, and urban heat island effects. Figure 1 is not an exhaustive list of the characteristics of heat-associated morbidity and mortality, nor does it indicate all the possible connections between these characteristics, but it outlines some of the major pathways by which racial or ethnic minorities or individuals of low socioeconomic status might have increased vulnerability as suggested by heat-health research. As research identifying the more proximal characteristics accumulates, findings will become more generalizable from place to place and over time, allowing more precise identification of target populations prior to and during extreme heat.

Acknowledgments This research was supported by a University of Michigan Graham Environmental Sustainability Institute Dow Postdoctoral Fellowship and grant R21-ES020156 from the U.S. National Institute of Environmental Health Sciences. I also thank Marie O'Neill for her assistance in preparing the manuscript and David Savitz for his review of the manuscript.

\section{Compliance with Ethics Guidelines}

Conflict of Interest C.J. Gronlund declares no conflicts of interest.

Human and Animal Rights and Informed Consent This article does not contain any studies with human or animal subjects performed by the author.

\section{References}

Papers of particular interest, published recently, have been highlighted as:

- Of importance

-. Of major importance

1.• Gubernot DM, Anderson GB, Hunting KL. The epidemiology of occupational heat exposure in the United States: a review of the literature and assessment of research needs in a changing climate. Int J Biometeorol. 2013. A review of occupational heat exposures, indicating that personal and work environment risk factors vary widely and that federal standards to protect workers from heat should be set.
2. Stallones RA, Gauld RL, Dodge HJ, Lammers TF. An epidemiological study of heat injury in army recruits. AMA Arch Ind Health. 1957;15(6):455-65.

3. Cook EL. Epidemiological approach to heat trauma. Mil Med. 1955;116(5):317-22.

4. Jones TS, Liang AP, Kilbourne EM, et al. Morbidity and mortality associated with the July 1980 heat wave in St. Louis and Kansas City, Mo. JAMA. 1982;247:3327-31.

5. IPCC. Climate Change 2007: the physical science basis. Contribution of Working Group I to the Fourth Assessment Report of the Intergovernmental Panel on Climate Change. Cambridge: Cambridge University Press; 2007.

6. Bi P, Williams S, Loughnan M, Lloyd G, Hansen A, Kjellstrom T, et al. The effects of extreme heat on human mortality and morbidity in Australia: implications for public health. Asia Pac J Public Health. 2011;23(2 Suppl):27S-36S.

7. - Yardley JE, Stapleton JM, Carter MR, Sigal RJ, Kenny GP. Is whole-body thermoregulatory function impaired in type 1 diabetes mellitus? Curr Diabetes Rev. 2013;9(2):126-36. A review of the associations between type I diabetes mellitus and heat exposure, with an emphasis on the physiologic mechanisms of this association.

8. Xu Z, Sheffield PE, Su H, Wang X, Bi Y, Tong S. The impact of heat waves on children's health: a systematic review. Int J Biometeorol. 2013. A review of the relatively small literature on children's health and heat, with a call to better understand the associations between heat and particular types of morbidity and mortality, such as pre-term birth, as well as the heat thresholds for each type and the heterogeneity between countries.

9.• Kravchenko J, Abernethy AP, Fawzy M, Lyerly HK. Minimization of heatwave morbidity and mortality. Am J Prev Med. 2013;44(3): 274-82. A broad review of populations vulnerable to heat (not just by race or socioeconomic status).

10.• Hansen A, Bi L, Saniotis A, Nitschke M. Vulnerability to extreme heat and climate change: is ethnicity a factor? Glob Health Action. 2013;6:21364. A review of racial and ethnic vulnerability to heat with a discussion of how U.S. research might apply to Australia and other places with increasing numbers of migrant workers and refugees.

11.• Ye X, Wolff R, Yu W, Vaneckova P, Pan X, Tong S. Ambient temperature and morbidity: a review of epidemiological evidence. Environ Health Perspect. 2012;120(1):19-28. A review of the smaller heat-morbidity (as opposed to heat-mortality) literature, including sociodemographic characteristics of vulnerability.

12. Xu Z, Etzel RA, Su H, Huang C, Guo Y, Tong S. Impact of ambient temperature on children's health: a systematic review. Environ Res. 2012;117:120-31.

13. Turner LR, Barnett AG, Connell D, Tong S. Ambient temperature and cardiorespiratory morbidity: a systematic review and metaanalysis. Epidemiology. 2012;4:594-606.

14. Yu W, Mengersen K, Wang X, Ye X, Guo Y, Pan X, et al. Daily average temperature and mortality among the elderly: a metaanalysis and systematic review of epidemiological evidence. Int $\mathrm{J}$ Biometeorol. 2012;56(4):569-81.

15. Wilson L, Black D, Veitch C. Heatwaves and the elderly - the role of the GP in reducing morbidity. Aust Fam Physician. 2011;40(8):63740 .

16. Hansen A, Bi P, Nitschke M, Pisaniello D, Newbury J, Kitson A. Older persons and heat-susceptibility: the role of health promotion in a changing climate. Health Promot J Aust. 2011;22(Spec No): S17-20.

17. Åström DO, Forsberg B, Rocklöv J. Heat wave impact on morbidity and mortality in the elderly population: a review of recent studies. Maturitas. 2011;69(2):99-105.

18. Kenny GP, Yardley J, Brown C, Sigal RJ, Jay O. Heat stress in older individuals and patients with common chronic diseases. CMAJ. 2010;182(10):1053-60. 
19. Hajat S, Kosatsky T. Heat-related mortality: a review and exploration of heterogeneity. J Epidemiol Community Health. 2010;64(9): 753-60.

20. Crandall CG, Gonzalez-Alonso J. Cardiovascular function in the heat-stressed human. Acta Physiol (Oxf). 2010;199(4): 407-23.

21. Gosling S, Lowe J, McGregor G, Pelling M, Malamud B. Associations between elevated atmospheric temperature and human mortality: a critical review of the literature. Climate Change. 2009;92(3):299-341.

22. Bhaskaran $\mathrm{K}$. The effects of ambient temperature on the incidence of myocardial infarction - a systematic review. Heart. 2009;95(21): 1760-9.

23. Basu R. High ambient temperature and mortality: a review of epidemiological studies from 2001 to 2008. Environ Health. 2009;8(1):40.

24. Luber G, McGeehin M. Climate change and extreme heat events. Am J Prev Med. 2008;35(5):429-35.

25. Kovats RS, Hajat S. Heat stress and public health: a critical review. Annu Rev Public Health. 2008;29:41-55.

26. Bouchama A, Matthies F, Shoukri M, Dehbi M, Mohamed G, Menne B. Prognostic factors in heat wave related deaths: a metaanalysis. Arch Intern Med. 2007;167(20):2170-6.

27. Reid CE, O'Neill MS, Gronlund CJ, Brines SJ, Brown DG, DiezRoux AV, et al. Mapping community determinants of heat vulnerability. Environ Health Perspect. 2009;117(11):1730-6.

28. Basu R, Samet JM. Relation between elevated ambient temperature and mortality: a review of the epidemiologic evidence. Epidemiol Rev. 2002;24(2):190-202.

29. Tan J. Commentary: people's vulnerability to heat wave. Int J Epidemiol. 2008;37(2):318-20.

30. Hajat S, O'Connor M, et al. Health effects of hot weather: from awareness of risk factors to effective health protection. Lancet. 2010;375:856-63

31. O'Neill MS, Ebi KL. Temperature extremes and health: impacts of climate variability and change in the United States. J Occup Environ Med. 2009;51(1):13-25.

32.• Sampson N, Gronlund CJ, Buxton MA, Catalano L, WhiteNewsome JL, Conlon KC, et al. Staying cool in a changing climate: reaching vulnerable populations during heat events. Glob Environ Chang. 2013;23:475-84. A qualitative study of vulnerability to heat, with results from open-ended interviews of residents of four U.S. cities. Crime, air conditioning use, social isolation, fan use, perception of exposure and risk perception are cited as barriers to staying cool.

33. Sheridan S. A survey of public perception and response to heat warnings across four North American cities: an evaluation of municipal effectiveness. Int J Biometeorol. 2007;52(1):3-15.

34.• Stoecklin-Marois M, Hennessy-Burt T, Mitchell D, Schenker M. Heat-related illness knowledge and practices among California hired farm workers in the MICASA study. Ind Health. 2013;51(1):47-55. Study of barriers to staying cool among migrant workers in California.

35.• Nitschke M, Hansen A, Bi P, Pisaniello D, Newbury J, Kitson A, et al. Risk factors, health effects and behaviour in older people during extreme heat: a survey in South Australia. Int J Environ Res Public Health. 2013;10(12):6721-33. Multivariable analysis of results from a telephone survey of 499 elderly Australians, identifying medication for mental health, various comorbidities and physical disability as associated with heat health outcomes.

36.• Banwell C, Dixon J, Bambrick H, Edwards F, Kjellstrom T. Sociocultural reflections on heat in Australia with implications for health and climate change adaptation. Glob Health Action. 2012; 5. doi: 10.3402/gha.v51i0.19277. Study of heat coping behaviors among the elderly in Australia including a discussion of heat risk perception in a population accustomed to hot temperatures.
37. Richard L, Kosatsky T, Renouf A. Correlates of hot day airconditioning use among middle-aged and older adults with chronic heart and lung diseases: the role of health beliefs and cues to action. Health Educ Res. 2011;26(1):77-88.

38. Maller CJ, Strengers Y. Housing, heat stress and health in a changing climate: promoting the adaptive capacity of vulnerable households, a suggested way forward. Health Promot Int. 2011;26(4): 492-8.

39. Hansen A, Bi P, Nitschke M, Pisaniello D, Newbury J, Kitson A. Perceptions of heat-susceptibility in older persons: barriers to adaptation. Int J Environ Res Public Health. 2011;8(12):4714-28.

40. Alberini A, Gans W, Alhassan M. Individual and public-program adaptation: coping with heat waves in five cities in Canada. Int J Environ Res Public Health. 2011;8(12):4679-701.

41. Larrieu S, Carcaillon L, Lefranc A, Helmer C, Dartigues J-F, Tavernier B, et al. Factors associated with morbidity during the 2003 heat wave in two population-based cohorts of elderly subjects: PAQUID and Three City. Eur J Epidemiol. 2008;23(4):295-302.

42. Semenza JC, Hall DE, Wilson DJ, Bontempo BD, Sailor DJ, George LA. Public perception of climate change: voluntary mitigation and barriers to behavior change. Am J Prev Med. 2008;35(5): 479-87.

43. Curriero FC, Zeger SL, Strug L, Heiner KS, Samet JM, Patz JA. Temperature and mortality in 11 cities of the eastern United States. Am J Epidemiol. 2002;155(1):80-7.

44. White-Newsome JL, O'Neill MS, Gronlund CJ, Sunbury TM, Brines SJ, Parker E, et al. Climate change, heat waves and environmental justice: advancing knowledge and action. Environ Justice. 2009;2(4):197-205.

45.• Zanobetti A, O’Neill MS, Gronlund CJ, Schwartz JD. Susceptibility to mortality in weather extremes: assessing effect modification by zipcode area level characteristic, personal characteristics and specific cause of admission in a multi-city case-only analysis. Epidemiology. 2013;24(6):809-19. Study of personal and ZIP code-level characteristics of heat-associated mortality among U.S. Medicare beneficiaries, identifying nonwhite race; pneumonia; cardiovascular, central nervous system and mental health conditions; low green space; education; poverty and population density as potential characteristics of vulnerability at the personal or area level.

46.• Fletcher BA, Lin S, Fitzgerald EF, Hwang SA. Association of summer temperatures with hospital admissions for renal diseases in New York State: a case-crossover study. Am J Epidemiol. 2012;175(9):907-16. Study of renal hospitalizations among residents of New York State, identifying race and income to be characteristics of vulnerability in this population. Specific renal outcomes associated with heat were also identified.

47. Medina-Ramon M, Zanobetti A, Cavanagh DP, Schwartz J. Extreme temperatures and mortality: assessing effect modification by personal characteristics and specific cause of death in a multi-city case-only analysis. Environ Health Perspect. 2006;114(9):1331-6.

48. O'Neill MS, Zanobetti A, Schwartz J. Modifiers of the temperature and mortality association in seven US cities. Am J Epidemiol. 2003;157(12):1074-82.

49. Noe RS, Jin JO, Wolkin AF. Exposure to natural cold and heat: hypothermia and hyperthermia Medicare claims, United States, 2004-2005. Am J Public Health. 2012;102(4):e11-8.

50. Lin S, Luo M, Walker RJ, Liu X, Hwang SA, Chinery R. Extreme high temperatures and hospital admissions for respiratory and cardiovascular diseases. Epidemiology. 2009;20(5):738-46.

51. Schwartz J. Who is sensitive to extremes of temperature?: a caseonly analysis. Epidemiology. 2005;16(1):67-72.

52. Kaiser R, Gotway CA, Daley WR, Le Tertre A, Schwartz J, Rubin $\mathrm{CH}$. The effect of the 1995 heat wave in Chicago on all-cause and cause-specific mortality. Am J Public Health. 2007;97 Suppl 1: S158-62. 
53. Green R, Basu R, Malig B, Broadwin R, Kim J, Ostro B. The effect of temperature on hospital admissions in nine California counties. Int J Public Health. 2010;55(2):113-21.

54. Madrigano J, Mittleman MA, Baccarelli A, Goldberg R, Melly S, von Klot S, et al. Temperature, myocardial infarction, and mortality: effect modification by individual- and area-level characteristics. Epidemiology. 2013;24(3):439-46. Study of characteristics of vulnerability to temperature-associated myocardial infarction and mortality in Worcester, Massachusetts, identifying area-level poverty as a potential characteristic of vulnerability to extreme heat in this population.

55.• Pillai SK, Noe RS, Murphy MW, Vaidyanathan A, Young R, Kieszak S, et al. Heat illness: predictors of hospital admissions among emergency department visits-Georgia, 2002-2008. J Community Health. 2014. Multivariable analysis of predictors of heat-related emergency department admission in the State of Georgia, identifying middle socioeconomic status, various comorbidities and district of residence as characteristics of vulnerability.

56. Basu R, Pearson D, Malig B, Broadwin R, Green R. The effect of high ambient temperature on emergency room visits. Epidemiology. 2012;23(6):813-20.

57. Uejio CK, Wilhelmi OV, Golden JS, Mills DM, Gulino SP, Samenow JP. Intra-urban societal vulnerability to extreme heat: the role of heat exposure and the built environment, socioeconomics, and neighborhood stability. Health Place. 2011;17(2): 498-507.

58. Anderson GB, Bell ML. Weather-related mortality: a study of how heat, cold, and heat waves affect mortality in the United States. Epidemiology. 2009;20(2):205-13.

59. Yardley J, Sigal RJ, Kenny GP. Heat health planning: the importance of social and community factors. Glob Environ Chang. 2011;21:670-9.

60. Taylor NAS. Ethnic differences in thermoregulation: genotypic versus phenotypic heat adaptation. J Therm Biol. 2006;31(1-2): 90-104. doi:10.1016/j.jtherbio.2005.11.007.

61. Harlan SL, Stefanov WL, Larsen L, Brazel AJ, Prashad L. Neighborhood microclimates and vulnerability to heat stress. Soc Sci Med. 2006;63(11):2847-63.

62. O'Neill MS, Zanobetti A, Schwartz J. Disparities by race in heatrelated mortality in four U.S. cities: the role of air conditioning prevalence. J Urban Health. 2005;82:191-7.

63. Harlan SL, Declet-Barreto JH, Stefanov WL, Petitti DB. Neighborhood effects on heat deaths: social and environmental predictors of vulnerability in Maricopa County, Arizona. Environ Health Perspect. 2013;121(2):197-204.

64. Ruiz JM, Steffen P, Smith TB. Hispanic mortality paradox: a systematic review and meta-analysis of the longitudinal literature. Am J Public Health. 2013;103(3):e52-60.

65. Klinenberg E. Heat wave: a social autopsy of disaster in Chicago. Chicago: University of Chicago Press; 2002.

66. Kalkstein AJ, Sheridan SC. The social impacts of the heat-health watch/warning system in Phoenix, Arizona: assessing the perceived risk and response of the public. Int J Biometeorol. 2007;52(1):4355 .

67. Michelozzi P, Russo A, D'Ovidio M, Cadum E, de Donato F, Bisanti L, et al. The impact of the summer 2003 heat waves on mortality in four Italian cities. Euro Surveill. 2005;10(7):161-5.

68. Zhang Y, Nitschke M, Bi P. Risk factors for direct heat-related hospitalization during the 2009 Adelaide heatwave: a case crossover study. Sci Total Environ. 2013;442:1-5.

69. Chan EY, Goggins WB, Kim JJ, Griffiths SM. A study of intracity variation of temperature-related mortality and socioeconomic status among the Chinese population in Hong Kong. J Epidemiol Community Health. 2012;66(4):322-7. Study of heat-related mortality in Hong Kong identifying individuals living in low socioeconomic districts and married individuals as more vulnerable.
70. Gouveia N, Hajat S, Armstrong B. Socio-economic differentials in the temperature-mortality relationship in Sao Paulo, Brazil. Int J Epidemiol. 2003;32.

71. Borrell C, Garcia-Olalla P, Muntaner C, Caylà JA, Marí-Dell'Olmo $\mathrm{M}$, Rodríguez-Sanz M, et al. Socioeconomic position and excess mortality during the heat wave of 2003 in Barcelona. Eur J Epidemiol. 2006;21(9):633-40.

72. Basu R, Ostro BD. A multicounty analysis identifying the populations vulnerable to mortality associated with high ambient temperature in California. Am J Epidemiol. 2008;168(6):632-7.

73. Bell ML, O'Neill MS, Ranjit N, Borja-Aburto VH, Cifuentes LA, Gouveia NC. Vulnerability to heat-related mortality in Latin America: a case-crossover study in Sao Paulo, Brazil, Santiago, Chile and Mexico City, Mexico. Int J Epidemiol. 2008;37(4):796804.

74. Ma W, Yang C, Tan J, Song W, Chen B, Kan H. Modifiers of the temperature-mortality association in Shanghai. China Int J Biometeorol. 2012;56(1):205-7.

75. Wang C, Chen R, Kuang X, Duan X, Kan H. Temperature and daily mortality in Suzhou, China: a time series analysis. Sci Total Environ. 2014;466-467:985-90.

76. Yang J, Ou CQ, Ding Y, Zhou YX, Chen PY. Daily temperature and mortality: a study of distributed lag non-linear effect and effect modification in Guangzhou. Environ Health. 2012;11(1):63.

77. Schifano P, Lallo A, Asta F, De Sario M, Davoli M, Michelozzi P. Effect of ambient temperature and air pollutants on the risk of preterm birth, Rome 2001-2010. Environ Int. 2013;61:77-87.

78. Schoeni RF, House JS, Kaplan GA, Pollack H. Making Americans healthier: social and economic policy as health policy. New York: Russell Sage Foundation; 2008.

79. Ng CF, Ueda K, Takeuchi A, Nitta H, Konishi S, Bagrowicz R, et al. Sociogeographic variation in the effects of heat and cold on daily mortality in Japan. J Epidemiol. 2014;24(1):15-24. Study of temperature-associated mortality in Japan. Population density, average income, cost of property rental, and number of nurses in a city modified the association.

80. Stafoggia M, Forastiere F, Agostini D, Biggeri A, Bisanti L, Cadum E, et al. Vulnerability to heat-related mortality. A multi-city, population-based base-crossover analysis. Epidemiology. 2006;17(3):315-23.

81. Vandentorren S, Croisier A, Declercq B, Mandereau-Bruno L, Ribéron J, Bretin P, et al. August 2003 heat wave in France: risk factors for death of elderly people living at home. Eur J Public Health. 2006;16(6):583-91.

82. Tran KV, Azhar GS, Nair R, Knowlton K, Jaiswal A, Sheffield P, et al. A cross-sectional, randomized cluster sample survey of household vulnerability to extreme heat among slum dwellers in Ahmedabad, india. Int J Environ Res Public Health. 2013;10(6): 2515-43.

83. Foroni M, Orlandi G, Daya G, Goldoni CA, Guerzoni A, Salvioli G, et al. A retrospective study on heat-related mortality in an elderly population during the 2003 heat wave in Modena, Italy: the Argento Project. J Gerontol A Biol Sci Med Sci. 2007;62(6):647-51.

84. Kaiser R, Rubin CH, Henderson AK, et al. Heat-related death and mental illness during the 1999 Cincinnati heat wave. Am J Forensic Med Pathol. 2001;22:303-7.

85. Fouillet A, Pavillon G, Clavel J, Bellec S, Rey G, Laurent F, et al. Excess mortality related to the August 2003 heat wave in France. Int Arch Occup Environ Health. 2006;80(1):16-24.

86. Naughton MP, Kaiser R, Rubin CH, Wilhelm JL, Henderson A, Mirabelli MC, et al. Heat-related mortality during a 1999 heat wave in Chicago. Am J Prev Med. 2002;22(4):221-7.

87. Kenney WL. Decreased cutaneous vasodilation in aged skin: mechanisms, consequences and interventions. J Therm Biol. 2001;26(4-5):263-71. 
88. Hansen A, Bi P, Nitschke M, Ryan P, Pisaniello D, Tucker G. The effect of heat waves on mental health in a temperate Australian city. Environ Health Perspect. 2008;116(10):1369.

89. Martinez M, Martinez J, Devenport L, Saussy J. Drug-associated heat stroke. South Med J. 2002;95(8):799-802.

90. Martin-Latry K, Bégaud B, Gabinski C, Verdoux H, Goumy M-P, Latry $\mathrm{P}$, et al. Psychotropic drugs use and risk of heat-related hospitalisation. Eur Psychiatry. 2007;22(6):335-8.

91. Stollberger C. Heat-related side-effects of neurological and nonneurological medication may increase heatwave fatalities. Eur $\mathrm{J}$ Neurol. 2009;16(7):879-82.

92. Argaud L, Marfisi A, Ducluzeau R, Ciorba D, Ferry T, Le Q-H, et al. Short- and long-term outcomes of heatstroke following the 2003 heat wave in Lyon, France. Arch Intern Med. 2007;167(20):2177-83.

93. Barbieri A, Biagioni E, Campagna A, Pinna C, Fruggeri L. Heat wave in Italy and hyperthermia syndrome. South Med J. 2006;99(8):829-31.

94. Levine M, LoVecchio F, Ruha AM, Chu G, Roque P. Influence of drug use on morbidity and mortality in heatstroke. J Med Toxicol. 2012;8(3):252-7.

95. Nordon C, Martin-Latry K, de Roquefeuil L, Latry P, Begaud B, Falissard B, et al. Risk of death related to psychotropic drug use in older people during the European 2003 heatwave: a populationbased case-control study. Am J Geriatr Psychiatr. 2009;17(12): 1059-67.

96. Oberlin M, Tubery M, Cances-Lauwers V, Ecoiffier M, Lauque D. Heat-related illnesses during the 2003 heat wave in an emergency service. Emerg Med J. 2010;27(4):297-9.

97. Abrahamson V, Wolf J, Lorenzoni I, Fenn B, Kovats S, Wilkinson $\mathrm{P}$, et al. Perceptions of heatwave risks to health: interview-based study of older people in London and Norwich, UK. J Public Health (Oxf). 2009;31(1):119-26.

98. Kosatsky T. Heat awareness and response among Montreal residents with chronic cardiac and pulmonary disease. Can J Public Health-Revue Canadienne de Sante Publique. 2009;100(3):237-40.

99. Braga AL, Zanobetti A, Schwartz J. The time course of weatherrelated deaths. Epidemiology. 2001;12(6):662-7.
100. Chestnut L, Breffle WS, Smith JB, Kalkstein LS. Analysis of the differences in hot-weather-related mortality across 44 U.S. metropolitan areas. Environ Sci Pol. 1998;1(1):59-70.

101. Medina-Ramon M, Schwartz J. Temperature, temperature extremes, and mortality: a study of acclimatization and effect modification in 50 United States cities. Occup Environ Med. 2007;64: 827-33.

102. Ostro B, Rauch S, Green R, Malig B, Basu R. The effects of temperature and use of air conditioning on hospitalizations. Am J Epidemiol. 2010;172(9):1053-61.

103. Anderson JO, Thundiyil JG, Stolbach A. Clearing the air: a review of the effects of particulate matter air pollution on human health. J Med Toxicol. 2012;8(2):166-75.

104. Allen RW, Adar SD, Avol E, Cohen M, Curl CL, Larson T, et al. Modeling the residential infiltration of outdoor $\operatorname{PM}(2.5)$ in the Multi-Ethnic Study of Atherosclerosis and Air Pollution (MESA Air). Environ Health Perspect. 2012;120(6):824-30.

105. O'Neill MS. Air conditioning and heat-related health effects. Appl Environ Sci Public Health. 2003;1(1):9-12.

106. Smargiassi A, Goldberg MS, Plante C, Fournier M, Baudouin Y, Kosatsky T. Variation of daily warm season mortality as a function of micro-urban heat islands. J Epidemiol Community Health. 2009;63(8):659-64.

107. Goggins WB, Ren C, Ng E, Yang C, Chan EY. Effect modification of the association between meteorological variables and mortality by urban climatic conditions in the tropical city of Kaohsiung, Taiwan. Geospat Health. 2013;8(1):37-44.

108. Xu Y, Dadvand P, Barrera-Gomez J, Sartini C, Mari-Dell'Olmo M, Borrell C, et al. Differences on the effect of heat waves on mortality by sociodemographic and urban landscape characteristics. J Epidemiol Community Health. 2013;67(6):519-25. Study of heat mortality in Barcelona finding census tract-level percentages of old buildings, manual workers and residents perceiving little greenness to be modifiers of the heat-mortality association.

109. Semenza JC, Rubin CH, Falter $\mathrm{KH}$, et al. Heat-related deaths during the July 1995 heat wave in Chicago. N Engl J Med. 1996;335:84-90. 